\title{
Mortality due to respiratory cancers in the coke oven plants of the Lorraine coalmining industry (Houillères du Bassin de Lorraine)
}

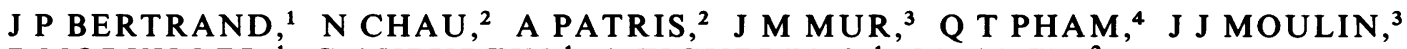 \\ P MORVILLER, ${ }^{1}$ G AUBURTIN, ${ }^{1}$ A FIGUEREDO, ${ }^{1}$ J MARTIN ${ }^{2}$ \\ From the Service de Médecine du Travail, ${ }^{1}$ Houillères du Bassin de Lorraine, Freyming-Merlebach; Unité \\ INSERM U 115 "Santé au Travail et Santé Publique: Méthodes et Applications"-Section de Statistique et \\ Epidémiologie, ${ }^{2}$ Informatique Médicale (Biomathématiques), Facultés de Médecine, BP 184; Institut National \\ de Recherche et de Sécurité (INRS);" and Unité INSERM U 14 "Physiologie Respiratoire", 454500 \\ Vandoeuvre-les-Nancy, France
}

\begin{abstract}
The main activity of the Houillères du Bassin de Lorraine (Lorraine Collieries), employing 23000 operatives and executives, is coalmining. The coke production is carried out by two coke oven plants with a workforce of respectively 747 and 552 workers. The coal coking process entails the emission of noxious products such as polycyclic aromatic hydrocarbons (PAH) from the ovens. The influence of occupational exposure on mortality due to respiratory cancers, and particularly to lung and upper respiratory and alimentary tracts cancer, was investigated among a cohort of 534 male workers from the two coke oven plants who had retired from work between 1963 and 1982. The job history of each subject has been precisely reconstructed by indicating the duration of exposure on the ovens, close to the ovens, and in maintenance occupations. The cohort mortality has been analysed according to the method of indirect standardisation with reference to the French male population and by a case-control study concerning the consumption of tobacco per cohort. The mortality due to lung cancer is 2.51 times higher than expected. This excess of mortality differs, but not significantly, between the two coke oven plants (standardised mortality ratio equals 3.05 and 1.75 respectively). It is not significantly higher among subjects exposed for more than five years, directly exposed on the ovens or working near the ovens or at maintenance occupations on the ovens (SMR $=2 \cdot 78)$, than among those exposed for less than five years (SMR $=2 \cdot 35$ ) or those not exposed at all. Even taking into account the excess of mortality due to lung cancers in the Moselle district (1.6 time that of France), the excess of lung cancers does not seem to be explained by the regional factor, or by tobacco and alcohol consumption. Although no significant relation was offered between lung cancer and the duration of exposure to PAH, even when taking smoking habits into account, the carcinogenic role of occupational nuisances cannot be excluded.
\end{abstract}

The Lorraine Collieries (Houillères du Bassin de Lorraine) have a workforce of 23000 employees. Coke is produced in two coke oven plants ( $A$ and $B$ ) with 747 employees in plant A and 552 in B. Plant A was the cradle of carbonisation as it was started in 1911; numerous extensions and new processes were set up there. The occupational hazards of coke production were reduced by the starting of A-III in 1963

Accepted 29 September 1986 thanks to the development of the stamping technique; this method consists of stamping the blend before charging it into the oven; the coal blend is then heated to $1350^{\circ} \mathrm{C}$ for 18 hours. Plant $\mathrm{B}$ was set into operation in 1955: there are 158 ovens, in six batteries, comprising three stamping charging-discharging machines. The nuisances in B may be considered as intermediate between the two above mentioned generations of A plant.

The coal coking process produces noxious volatile matters, whose toxicity is linked to the emission of 
polycyclic aromatic hydrocarbons (PAH), amounting to $2 \%$ or $3 \%$ of the particulate weight and ranging between $3 \%$ and $6 \%$ of the benzene soluble fraction. ${ }^{1}$ The risk of cancer linked to exposure to tar and PAH has been repeatedly investigated. ${ }^{2-23}$

The present study investigated the influence of this occupational exposure on mortality from lung cancer and upper respiratory and alimentary tract cancer (URAC) among workers who have constantly worked on the ovens or near ovens and among maintenance workers with intermittent exposure on the ovens. Smoking habits, another potential factor of lung cancer, were taken into consideration.

\section{Material and methods}

\section{POPULATION}

The population investigated was a cohort of male manual workers from the coke oven plants A and B who had retired from working in the coke oven plants after 1 January 1963. They were born between 1902 and 1935. The period of investigation ranged from 1 January 1963 to 31 December 1982.

Table 1 shows the age distribution of the study population. The number of employees is a little higher in plant $A$ than in plant $B$. Nineteen per cent of the cohort have died. Causes of death have been established from the medical records kept in hospitals or by occupational physicians, by general practitioners, and by physicians from the health services. We looked for the main and the secondary causes of death, the pathological elements known in the subject's life, the reasons for admission to hospital, alcohol consumption, and smoking habits. Information gathered from the subject's relatives enabled us to complete and confirm the data recorded in the medical records.

Each subject's job history has been compiled from the personnel work and health descriptions noted in the administrative records and the occupational medical record. For this, we had to rely on the contributions of the foremen. It consisted of breaking down the job history into a series of occupations for which we had to define:

The workplace-A distinction was made between occupations in each coke oven plant but also outside coke oven plants: in a power plant, in the chemical industry, underground, in other typical mining activities, and in administrative jobs.

Table 1 Distribution of the study population

\begin{tabular}{lccc}
\hline & Plant $A$ & Plant B & Total \\
\hline Living & 229 & 201 & 430 \\
Dead & 60 & 44 & 104 \\
Total & 289 & 245 & 534 \\
\hline
\end{tabular}

Type of occupational nuisances - coal dust, otherz particles, paint, welding, gas, smokes, benzene, phe $\frac{\mathbb{2}}{2}$ nol, sulphates, pitch, and tars.

The aim of the study was to analyse the risk of cancer linked to the exposure to the specific nuisanceso of coke oven plants, categorised according to task: 흠

Exposure on the ovens - Support setter, shield set ter, oven regulator, door cleaner, column cleaner, tari cleaning tube operator.

Exposure near the ovens-Pusher machine operator, stamper, switch operator, coke car, etc ....

Intermittent exposure on ovens-Maintenance per $\overrightarrow{\vec{H}}$ sonnel on ovens, fitter, electrician, maintenances worker, fireproof bricklayer, etc. ...

These three categories are characterised by the degree of exposure to dust, gas, and fumes. Mainte $+\vec{\perp}$ nance personnel who are not in direct contact with theo ovens, and occupations with no direct exposure tơ dust, gas, and fumes are considered as not or slightlye exposed. This last category also comprises those working at the revolving kiln, a process generatingfew harmful pollutants.

STATISTICAL METHODS USED

The study of the cohort mortality has been conductedo with the national male population as a reference (sta $\stackrel{\infty}{-}$ tistics of INSERM ${ }^{24}$ and INSEE ${ }^{25}$ ). The method of indirect standardisation consists in calculating the expected number of deaths by applying the reference mortality to the age groups of the cohort, for each year, from 1963 to $1982^{26}$; from the observed (O) anco expected (E) numbers of deaths the standardised mor tality ratio (SMR) may be calculated. ${ }^{27-30}$

We have tested the null hypothesis, Ho: "the cohor mortality is equal to the reference population mor tality" considering that $\mathrm{O}$ follows a Poisson distribus tion with $\mathrm{E}$ as a parameter (bilateral test). ${ }^{26}$

A comparison of the mortality in severaB subgroups - for example, comparison of mortalities between the two cokeries or between groups of occupational exposure-was conducted according tø the homogeneity chi-square test of the corresponding SMR. ${ }^{26}$

To evaluate the influence of occupational exposuros on lung cancer mortality, it is important to tak smoking habits into account. Case control analysis of deaths from lung cancer is included in the cohor study. For each death due to lung cancer, we chose two controls who had died from a cause other than respiratory cancer. The matching criteria were year of birth, age at death, and smoking habits. The exposures to dust, gas, and fumes of the cases and the controls were compared by means of two methods: $\stackrel{\infty}{\rightarrow}$

(1) the distribution by categories of duration of exposure (less than five years, from five to nine yearso and 10 years and more) were compared by means of 
Mortality due to respiratory cancers in the coke oven plants of Lorraine coalmining industry

Table 2 Distribution of dead subjects according to age and main cause of death. CIM codes, 9 th rev, ${ }^{34}$ are indicated in parentheses

\begin{tabular}{lcccc}
\hline & \multicolumn{3}{c}{ Age at death (years) } \\
\cline { 2 - 4 } Main causes of death & $\leqslant 54$ & $55-64$ & $\geqslant 65$ & Total \\
\hline Total No of cancers (140-209) & 2 & 23 & 10 & 35 \\
Infectious diseases (000-139) & - & 1 & 1 & 2 \\
Cardiovascular causes (390-459) & - & 21 & 15 & 36 \\
$\begin{array}{l}\text { Respiratory diseases (460-519) } \\
\text { Cirrhosis and alcoholism (303, }\end{array}$ & 1 & 1 & 1 & 3 \\
$\begin{array}{l}\text { 571-0) } \\
\text { Accidents and other violence }\end{array}$ & 5 & 4 & 1 & 10 \\
$\begin{array}{l}\text { Other causes } \\
\text { Undefined, unknown causes } \\
\quad(780-799)\end{array}$ & - & 3 & 1 & 4 \\
All causes & 2 & 4 & 5 & 11 \\
\hline
\end{tabular}

Armitage's statistical test of homogeneity of proportions $^{31}$;

(2) the differences in individual exposures were analysed by means of Wilkinson's signed rank test $^{3233}$ (keeping only one control, that which matches the case best).

Statistical tests have been conducted with a first order risk of 5\%. A non-significant result is referred to as NS. In the case of significant results the degree of significance $p$ is quoted.

\section{Results}

The figure shows the histogram of the age of the subjects alive on 1 January 1983 and of the employees who died during the investigated period. In the cohort
Table 3 Distribution of cancers by site. CIM codes, 9 th rev, ${ }^{34}$ are indicated in parentheses

\begin{tabular}{lllll}
\hline & \multicolumn{2}{l}{ Age at death (years) } & \\
\cline { 2 - 4 } Main cause of death & $\leqslant 54$ & $55-64$ & $\geqslant 65$ & Total \\
\hline Lung (162) & 1 & 12 & 4 & 17 \\
URAC (140-149, 160-161) & - & 2 & - & 2 \\
Oesophagus (150) & - & - & 1 & 1 \\
Stomach (151) & - & 2 & 2 & 4 \\
Intestines (152) & - & 2 & 2 & 4 \\
Pancreas (157) & - & - & 1 & 1 \\
Genitourinary tract cancer & $-180-189)$ & 1 & - & 1 \\
Haemopathies (200-209) & - & 2 & - & 3 \\
Other cancers & 1 & 23 & 10 & 35 \\
Total No of cancers (140-209) & 2 & 23 \\
\hline
\end{tabular}

URAC: Upper respiratory and alimentary tract cancer.

considered those aged 55-64 accounts for the largest part (59\% of the dead subjects and $66 \%$ of the living). Both dead and living subjects have the same mean age $(62 \pm 6)$.

Table 2 shows the distribution of the main causes of death. Undefined causes of death, most of them referred to as unexpected deaths and unknown causes, account for $11 \%$ of the total, which is nearly the same rate as in the national statistics established by the INSERM.

Cancers account for $34 \%$ of deaths; their distribution by site is given in table 3 . Lung cancers represent $16 \%$ of the causes of death and $49 \%$ of the cancers; $76 \%$ of the subjects who died from lung cancer were under 65 .

In table 4 the cohort mortality is compared with

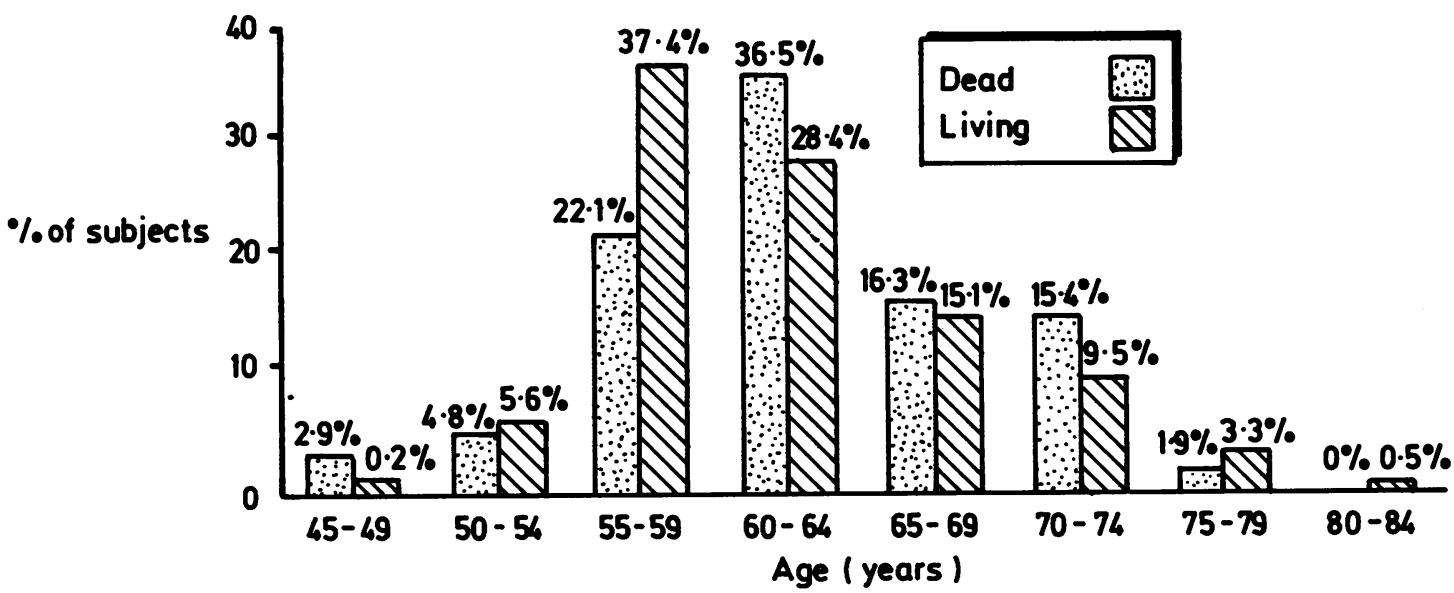

Mean age of dead subjects $=62 \cdot 5+6 \cdot 1$ years
Mean age of living subjects $=62 \cdot 3+6 \cdot 2$ years

Age histogram of dead and living subjects on 1 January 1983. 
Table 4 Comparison of the cohort mortality with the French male mortality

\begin{tabular}{lrll}
\hline Main cause of death & $O$ & $O / E$ & $(1)$ \\
\hline Cancers: & 35 & $1 \cdot 15$ & NS \\
Lung & 17 & $2 \cdot 51$ & p < 1\% \\
URAC & 2 & 0.47 & NS \\
Other & 16 & 0.83 & NS \\
Other causes & 69 & 1.08 & NS \\
All causes & 104 & $1 \cdot 10$ & \\
\hline
\end{tabular}

(1) Test of equality between $O$ and $E$.

URAC: Upper respiratory and alimentary tract cancer.

that of the whole French male population. The overall mortality of the cohort (all causes together) is a little higher than expected, but not significantly so $(\mathrm{SMR}=1 \cdot 10)$.

Although the number of observed cancers is higher than expected, this excess is not significant (SMR = $1 \cdot 15)$. Mortality due to lung cancer in our cohort is significantly higher than expected $(\mathrm{SMR}=2 \cdot 51)$. On the other hand, there is a less than average mortality (not statistically significant) for upper respiratory and alimentary tract cancer $(S M R=0.47)$. The other cancers are also underrepresented in our sample $(\mathrm{SMR}=\mathbf{0} \cdot 83)$.

\section{COMPARISON OF MORTALITY BETWEEN THE} TWO COKE OVEN PLANTS

Table 5 analyses separately the mortality of the operatives from each of the two plants by comparison

with the mortality of the French population. The slight non-significant excess of mortality is almos the same in the two plants $(\mathrm{SMR}=1.07$ and: SMR $=1 \cdot 15$ ). Lung cancers, however, account fo $63 \%$ of cancers and $20 \%$ of deaths for plant $A ; 31 \%$ of cancers and $11 \%$ of deaths for plant $B$. The excess of lung cancer mortality is more pronounced for $A \bar{m}$ $(S M R=3.05)$ than for $B(S M R=1.75)$. It is significant $(p<0.01)$ for A but not for B. This relative difference could be explained by the more noxious effects of the old plant $A$ which was trans? formed in 1963. The other types of cancer are rela $\overrightarrow{-}$ tively more frequent for $B(S M R=1 \cdot 13)$ than for $A_{S}$ (SMR $=0.50)$ but the difference is not significant. It should nevertheless be noted that the analysis has been conducted on a small number of cases.

\section{INFLUENCE OF EXPOSURE TO DUST, GAS,} AND FUMES

Let us recall that this exposure concerns subjects working constantly on ovens, near ovens, and maintenance personnel with intermittent exposure on ovens The degree of exposure is determined by the workin duration at these workplaces. Table 6 gives the mor tality of workers not exposed or exposed for less that $\overrightarrow{0}$ five years compared with that of workers exposed fopo five years or more.

As above, the SMR of subgroups has been calcuo lated with reference to the French male populations Only lung cancer mortality is significantly higher that

Table 5 Mortality of workers from the coke oven plants

\begin{tabular}{|c|c|c|c|c|c|c|c|}
\hline \multirow[b]{2}{*}{ Main cause of death } & \multicolumn{3}{|c|}{ Plant A } & \multicolumn{3}{|c|}{ Plant B } & \multirow{2}{*}{ (2) } \\
\hline & $O$ & $S M R$ & (1) & $O$ & $S M R$ & (1) & \\
\hline $\begin{array}{l}\text { Cancers: } \\
\text { Lung } \\
\text { URAC } \\
\text { Other } \\
\text { Other causes }\end{array}$ & $\begin{array}{r}19 \\
12 \\
1 \\
6 \\
41\end{array}$ & $\begin{array}{l}1.07 \\
3.05 \\
0.41 \\
0.52 \\
1.07\end{array}$ & $\begin{array}{l}\text { NS } \\
\text { p }<1 \% \\
\text { NS } \\
\text { NS } \\
\text { NS }\end{array}$ & $\begin{array}{r}16 \\
5 \\
1 \\
10 \\
28\end{array}$ & $\begin{array}{l}1.27 \\
1.75 \\
0.55 \\
1.27 \\
1.08\end{array}$ & $\begin{array}{l}\text { NS } \\
\text { NS } \\
\text { NS } \\
\text { NS } \\
\text { NS }\end{array}$ & $\begin{array}{l}\text { NS } \\
\text { NS } \\
\text { NS } \\
\text { NS } \\
\text { NS }\end{array}$ \\
\hline All causes & 60 & 1.07 & NS & 44 & $1 \cdot 15$ & NS & NS \\
\hline
\end{tabular}

(1)Test of equality between $O$ and $E$.

(2) Homogeneity chi-square test of SMR corresponding to the coke plants.

URAC: Upper respiratory and alimentary tract cancer.

Table 6 Mortality and occupational exposure to dust, gas, and fumes

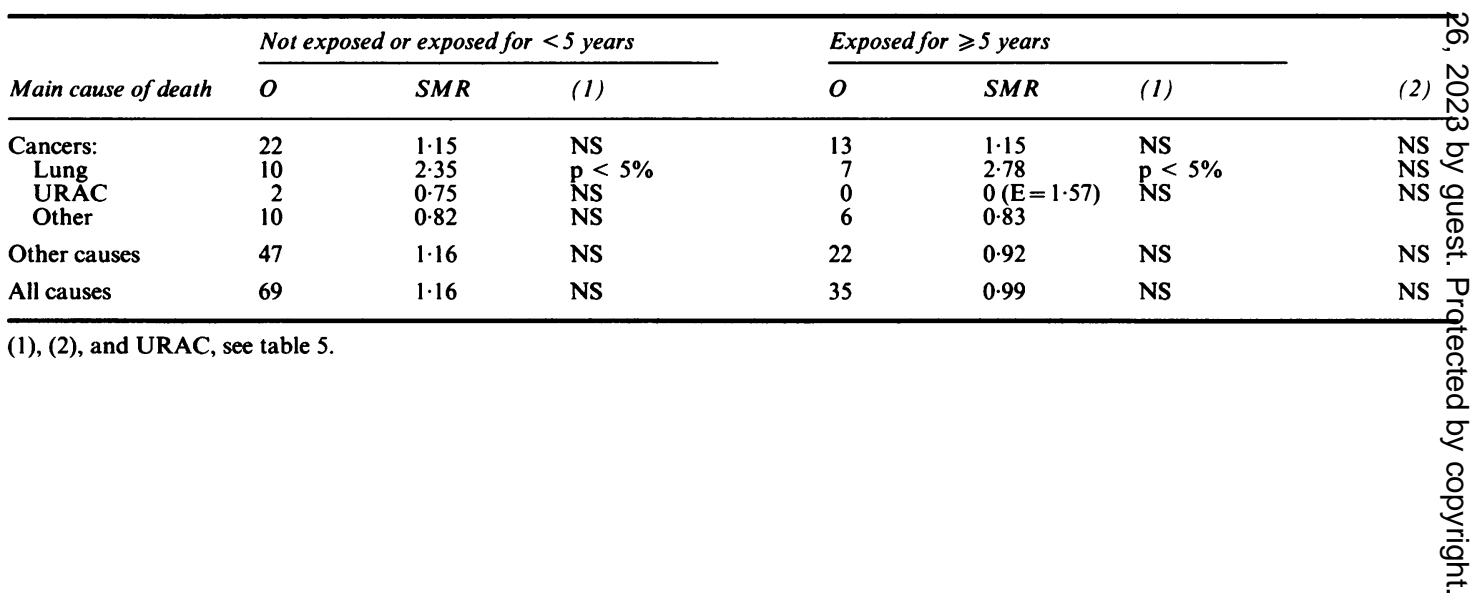


expected in the two groups. The SMR of the group of men exposed for five years or more equals $2 \cdot 78$, which is a little higher than that of those non-exposed or exposed for less than five years $(2 \cdot 35)$. The homogeneity test of the corresponding SMR does not show a significant difference of mortality due to lung cancer between the two groups.

The statistical analysis has also been carried out on other criteria of exposure-namely, sole exposure on the ovens, exposure for which the carcinogenic risk appeared the highest in the studies of Lloyd and Redmond. ${ }^{17}$ The results of the investigation, which were, with a smaller number of subjects, similar to the results related to exposure to dust, gas, and fumes are not shown here.

\section{CASE-CONTROL ANALYSIS OF DEATHS FROM LUNG CANCER}

The influence of tobacco as an extra-occupational risk has been investigated for all subjects who died. We managed to obtain details of the smoking habits of 77 of the 104 dead subjects $(74 \%)$. Table 7 shows the distribution of causes of death among smokers and non-smokers. The proportion of deaths due to cancer is linked to smoking habits: $29 \%$ cancers for non-smokers, $42 \%$ cancers for smokers but this difference is not significant.

Smoking significantly increases the risk of lung cancer which is why we have conducted an analysis of pairmates as regards the influence of occupational exposure, matching on their smoking habits: the proportion of subjects exposed to dust, gas, and fumes is more important among those who died from lung cancers $(47 \cdot 1 \%)$ than among their pairmates $(35 \cdot 2 \%)$, but the difference is not statistically significant (table 8). In addition, the Wilcoxon test does not show any significant difference in occupational exposure between the cases and their pairmates.

\section{Discussion}

This study analysed the cancer mortality of the coke oven plants among retired workers in the Lorraine coalmining industry. Thus we have necessarily to deal with subjects older than 55, except for a few workers who retired early. As the ages characterised by a high

Table 7 Cause of death and smoking habits

\begin{tabular}{lccc}
\hline Main cause of death & Non-smokers & Smokers & Unknown \\
\hline Cancers: & 7 & 22 & 6 \\
Lung & 1 & 14 & 2 \\
Digestive system & 4 & 5 & 2 \\
Other & 2 & 3 & 2 \\
Other causes & 17 & 31 & 21 \\
All causes & 24 & 53 & 27 \\
\hline
\end{tabular}

Table 8 Distribution of the lung cancers and the case-controls with regard to the exposure to dust, gas, and fumes (DGF)

\begin{tabular}{lcll}
\hline Exposure to DGF & None & $1-9$ years & $\geqslant 10$ years \\
\hline Lung cancers & 9 & 4 & 4 \\
Case-controls & 22 & 3 & 9 \\
\hline
\end{tabular}

proportion of deaths from lung cancers range between 45 and 74 and the deaths occurring earlier than 55 happened during the working period (out of 65 deaths observed, seven were from lung cancer), the exclusion of the latter (those dying before reaching retirement age) may lead us to underestimate the mortality due to lung cancers. The investigated cohort could have been made up of the total number of workers present in the coke plants at the beginning of the observation period, in 1963. This was not possible because the mining social security loses track of the dismissed workers and of those who resigned or were transferred to other plants. Sometimes, their departure is due to health reasons.

The percentage of unknown causes of death $(11 \%)$ is considered satisfactory since it corresponds to national statistics.

Let us recall that the analysis of mortality is conducted with reference to the French male population. Since the mortality due to lung cancers is 1.3 times higher in Lorraine than in the whole country $(1.6$ times higher in the Moselle district which is a part of the region of Lorraine) for the years 1968, 1969, and 1970 it would be more appropriate to take a regional reference into account, but the statistics are not available for the years 1963-74.

Some studies on causes of death and occupation have shown a global mortality that is lower than average by comparison with the regional or national reference, a phenomenon known as the healthy worker effect. $^{8-35}$ In our. study the number of deaths is slightly higher than expected. The mortality from cancers of all locations is not significantly higher than that of the French population. With regard to nonfatal cancers, no skin cancer has been observed.

Mortality due to lung cancer is $\mathbf{2 . 5}$ times higher than expected. Even if one takes into account the excess of mortality due to lung cancer in Moselle the excess of lung cancers among the cohort cannot be explained solely by the regional factor nor by the general excess of lung cancers among unskilled workers. ${ }^{36}$ Besides, it cannot be accounted for by the confounding factors tobacco and alcohol because the deaths from upper respiratory and alimentary tract cancer are underrepresented in this investigation. The excess of lung cancers due to occupational exposure is plausible even though there is no correlation with duration of exposure to dust, gas, and fumes. 
Our results may be compared with those of other studies conducted on coke oven plants. ${ }^{58121315182237}$ In 1971 Lloyd showed that in the coke oven plants of the Alleghany County, the mortality due to lung cancers among the men working on coke ovens was 2.5 times higher than that observed among other metallurgists. ${ }^{12}$

Lloyd ${ }^{12}$ and Redmond et $a l^{17}$ showed that the frequency of lung cancers was linked to the duration and relative level of exposure on the ovens. In Pennsylvania the men employed on the ovens for five years or more had a rate of mortality due to lung cancers 3.5 times higher than expected, whereas the rate of all the men working on ovens was 2.5 times higher than the normal rate. Redmond et al confirmed the existence of a relation between work on ovens and lung cancers $^{17}$ : the relative risk of lung cancers is $2 \cdot 1$ times higher than average for men working only near the ovens, 3.2 for men working above and near, and 6.9 for those working above the ovens.

Sakabe et al studied the mortality of 4655 retired employees from 36 metal works in Japan ${ }^{22}$ : the mortality due to cancer of all sites and lung cancers was about equal to the expected frequency. They noticed, however, an excessive mortality due to lung cancers among the retired employees from four coke oven plants, eight cases of lung cancer for 3.4 expected; the difference was significant, though the investigated population was small.

Jacobsen and Hurley conducted an investigation on mortality in the British industries of coal carbonisation and tar distillation, studying a population of 4836 people from 1966 to $1975 .^{8}$ Deaths due to lung cancers were $29 \%$ higher than expected, the difference being statistically significant. Important variations were also noticed between the different plants investigated.

The variations of results among the different epidemiological surveys may be explained partly by methodological differences (definition of cohort, choice of reference population) and by the differences in technological processes and working methods on the batteries of ovens and also by differences in oven temperatures. These factors influence the type and concentration of toxic products generated by the ovens. They can also account for the relative high mortality due to lung cancers that was noticed in plant A compared with plant B $(\mathrm{SMR}=3.05 v 1.75)$ in our study.

One may remark that dust, gas, and fumes do not constitute the only potential risks of lung cancers in those industries where there are also other harmful products such as asbestos, fumes, coal, or tar.

\section{Conclusion}

The mortality of the cohort of 534 retired workers from the Lorraine Collieries coke oven plants has been compared with that of the French male popts lation. Among the 104 registered deaths, there was significant excess of mortality due to lung cancers (1037 cases observed; SMR = 2.51). Although there is no evidence of a relation between lung cancers and duration of exposure to $\mathrm{PAH}$, the carcinogenic role $\overline{\mathrm{of}}$ occupational nuisances cannot be excluded. Therब fore, it is to be hoped that preventive arrangements will be taken to limit pollution at working places and to reduce the number of workers exposed.

We express our sincerest thanks to the health can physicians, the attending physicians, the hospital ph sicians of Mine Social Security (SSM) and "Hosp talor," and also to the managers and deputies of the coke oven plants and to the investigators of thes Lorraine Coalmining occupational medicine for thein valuable cooperation. We also express our gratitude to Professor M Manciaux who agreed to read ove this paper. We thank Mr A Denis, engineer at the Charbonnages de France who translated this report The typing of the successive versions of the mane script was performed by $\mathbf{M}$ Schmitt, M Graesel, $\bar{\Phi}$ Bour, A Croquin, $M$ Loeffler, and I Ringenback and we give them our warmest thanks.

Requests for reprints to: N Chau, INSERM U115.

\section{References}

1 National Institute for Occupational Safety and Health. Criteria for a recommended standard. Occupational exposure to coal to⿸\zh14 products. Cincinnati: NIOSH, 1977. (DHEW publ NG 78-107.)

2 Bertrand JP. Mortalité par cancers broncho-pulmonaires dans bassin houiller Lorrain, XXIIIèmes journées de perfectionnement des médecins des houillères. Vol 2. Paris: Chaß bonnage de France, 1981:18-41.

3 Davies GM. A mortality study of coke oven workers in two south Wales integrated steelworks. Br J Ind Med 1977;34:291-7.

4 Doll R, Fischer REW, Gammon EJ, et al. Mortality of gas workers with special reference to cancers of the lung and bla\& der, chronic bronchitis, and pneumoconiosis. $\mathrm{Br} J$ Ind Meg 1965;22:1-12.

5 Falk HL, Jurgelski WJ. Health effect of coal mining and com bustions: carcinogens and cofactors. Environ Health Perspecs 1979;33:203-26.

6 Haguenoer JM, Frimat P, Bonneterre J, Vennin P. Les cancers professionnels. Paris: Technique et documentation Lavoisiefs 1982.

7 Houten L, Bross IDJ, Viadana E. Occupational cancers in mexी exposed to metals. Adv Exp Med Biol 1977;91:93-102.

8 Jacobsen M, Hurley JF. Mortality at British factories engaged in coal carbonisation and tar distillation. Edinburgh: Institute Occupational Medicine, 1977.

9 James WRL. Primary lung cancer in south Wales coal-worke with pneumoconiosis. $\mathrm{Br} J$ Ind $\mathrm{Med}$ 1955;12:87-91.

10 Kennaway E, Kennaway N. A further study of the incidence of cancer of the lung and larynx. Br J Cancer 1947;1:260-5.

11 Kennaway E, Kennaway N. The incidence of cancer of the lurn in coalminers in England and Wales. Br J Cancer 1953;7:10-

12 Lloyd JW. Long-term mortality study of steelworkers: respir解 
tory cancers in coke plant workers. $J$ Occup Med 1971;13:53-68.

13 Lloyd JW. Lung cancer mortality in Allegheny county coke-plant workers. Pittsburgh: University of Pittsburgh, 1966. (DSc Hyg thesis.)

$14 \mathrm{Manz}$ A. Harnwegskarzinome bei Beschäftigten der Gasindustrie. Münchener Medizinishe Wochenschrift 1976;118:65-8.

15 Mazumbar S, Redmond C, Sollecito W, Sussman N. An epidemiological study of exposure to coal tar pitch volatiles among coke oven workers. J Air Pollut Control Assoc 1975;25:382-9.

16 Mooney F. Carcinoma of the lung in Lancashire coalminers. Thorax 1979;34:826-7.

17 Redmond CK, Ciocco A, Lloyd JW, Rusch HW. Long-term mortality study of steelworkers: mortality from malignant neoplasms among coke oven workers. J Occup Med 1972;14:621-9.

18 Reid DD, Buck C. Cancer in coking plant workers. Br J Ind Med 1965;13:265-72.

19 Robertson JMD, Ingalls TH. A mortality study of carbon black workers in the United States from 1935 to 1974. Arch Environ Health 1980;35:181-6.

20 Rockette HE. Cause specific mortality of coalminers. J Occup Med 1977;19:795-808.

21 Rooke GB, Ward FG, Dempsey A, Dowler JB, Whitaker CJ. Carcinoma of the lung in Lancashire coalminers. Thorax 1979;34:229-33.

22 Sakabe H, Tsuchiya K, Takerura N, et al. Lung cancer among coke oven workers. Report to labour standard bureau, Ministry of Labour, Japan. Japanese Journal of Industrial Health 1975;13:57-68.

23 International Agency for Research on Cancer. Monographs on the evaluation of the carcinogenic risk of chemicals to humans. Polynuclear aromatic compounds. Vol 34. Part 3. Coke production. Lyon: IARC, 1985:101-31.

24 Institut National de la Santé et de la Recherche Médicale. Statis- tique des causes médicales de décès. Vol 1. Résultats France entière. 1963-1982. Paris: INSERM.

25 Institut National de la Statistique et des Etudes Economiques. Statistique des causes de décès. 1963-1984. Paris: INSEE.

26 Hill C, Rezvani A, Kramar A. Comparaison de la mortalité d'une cohorte à la mortalité d'une population de référence. Principe, nombre de décès attendus nécessaire et puissance du test. Rev Epidémiol Santé Publique 1984;32:330-5.

27 Breslow NE, Lubin JH, Marek P, Langholz B. Multiplicative models and cohort analysis. Journal of the American Statistical Association 1983;78:1-12.

28 Mantel N, Haenzel W. Statistical aspects of the analysis of data from retrospective studies of disease. JNCI 1959;22:719-48.

29 Mantel N. Ranking procedures for arbitrarily restricted observation. Biometrics 1967;23:65-78.

30 Peto P, Pike MC, Armitage P, et al. Design and analysis of randomized clinical trials requiring prolonged observation of each patient. Br J Cancer 1977;35:1-39.

3.1 Armitage P. Statistical methods in medical research. Oxford: Blackwell Scientific Publication, 1971.

32 Lebart L, Morineau A, Fénelon JP. Traitement des données statistiques. Méthodes et programmes. Paris: Dunod, 1982.

33 Kendall M, Stuart A. The advanced theory of statistics. Vol 2. Inference and relationship. London: Charles Griffin and Co Ltd, 1979.

34 Organisation Mondiale de la Santé (OMS). Classification internationale des maladies. 9th rev (vol 1, rev 1975; vol 2, rev 1977). Genéve: OMS.

35 Bertin M. Enquête sur la mortalité par cancer parmi le personnel en activité à EDF-GDF. Archives des Maladies Professionnelles de Médecine du Travail et de Sécurité Sociale 1983;44:329-38.

36 Sarraci R. Aspects socio-écomoniques du cancer du poumon. Schweiz Med Wochenschr 1979;109:820-4.

37 Bross IDJ, Viadana E, Houten L. Occupational cancer in men exposed to dust and other environmental hazards. Arch Environ Health 1978;33:300-7. 